\title{
RESTRICTED CURVATURE IN THE MINKOWSKI PLANE
}

\section{Mostafa GHANDEHARI}

Abstract. A geometric proof for the following problem is given: Let $E$ be the unit circle in a Minkowski plane. Let $C$ be any continuously differentiable closed curve with length $l(C)$ (measured in Minkowski metric). Assume $\left|\kappa_{e}(C,).\right| \leqslant k \kappa_{e}(E,$.$) and \kappa_{e}(E,$.$) denote Euclidean$ curvatures. Then $C$ can be contained in a similar copy of the unit disk translated and magnified by a factor of

$$
\frac{l(C)}{4}-\frac{1}{4 k}(l(E)-4) .
$$

Mathematics subject classification (2010): 52A38. Keywords and phrases: geometric inequalities; Minkowskian geometry; restricted curvature.

\section{REFERENCES}

[1] R. V. Benson, Euclidean Geometry and Convexity, McGraw-Hill, 1966.

[2] O. Biberstein, Eléments de géométrie différentielle Minkowskienne, Thése, Universite de Montreal, 1957.

[3] W. BlaschKe, Kreis and Kugel, Viet, Leipzig, 1916; reprint, Chelsa, New York, 1949.

[4] V. G. BoltyanskiI, Mathematical Methods of Optimal Control, Nauka, Moscow, 1966; English transl., Holt, Rinehart, and Winston, New York, 1948.

[5] H. Busemann, The foundations of Minkowskian geometry, Comm. Math Helv., 24 (1950), pp. 156187.

[6] G. D. Chakerian, H. H. Johnson, And A. Vogt, A geometric inequality for plane curves with restricted curvature, Proc. Amer. Math. Soc., 57 (1076), pp. 122-126.

[7] G. D. Chakerian, A characterization of curves of constant width, Amer. Math. Monthly, 81 (1974), pp. 146-149.

[8] G. D. Chakerian, And M. S. Klamkin, Minimal covers for closed curves, Math. Mag., 46 (1973), pp. 55-61.

[9] G. D. Chakerian, Integral geometry in the Minkowski plane, Duke Math. J., 29 (1962), pp. 375382.

[10] L. E. Dubins, On curves of minimal length with a constraint on average curvature, and with prescribed initial and terminal positions and tangents, Amer. J. Math., 79(1957), pp. 497-516.

[11] W. H. Fleming, AND R. W. Rishel, Deterministic and stochastic Optimal Control, Springer-Verlag, 1975.

[12] I. M. Gelfand, And S. V. Fomin, Calculus of Variations, Prentice Hall, 1963.

[13] M. Ghandehari, Controlling Curvature in the Minkowski Plane, (English summary), J. Math. Anal. Appl. 252 (2000), no. 2, 951-958.

[14] P. A. GRIfFITHS, Exterior Differential Systems and the Calculus of Variations, Progress in Mathematics, Birkhäuser, 1983.

[15] R. Hermann, Differential Geometry and the Clculus of Variations, Academic Press, 1968.

[16] R. Is AACS, Differential Games, Wiley, 1965, pp. 8-13.

[17] H. H. Johnson, An application of the maximum principle to the geometry of plane curves, Proc. Amer. Math. Soc., 44(1974), pp. 432-435.

[18] D. Koutroufiotis, On Blaschke's rolling theorems, Arch. Math., 23 (1972), pp. 655-660.

[19] D. LaugWitz, Konvexe mittelpunktsbereiche und normierte Räume, Math. Z., 61 (1954), pp. 235244. 
[20] G. Leitmann, The Calculus of Variations and optimal Control, Plenum press, 1981.

[21] Z. A. MelzaK, Plane motion with curvature limitation, J. Soc. Indust. Appl. Math., 9 (1961), pp. $422-432$.

[22] H. Minkowski, Theorie der Konvexen Körper, Insbesondere Begründung Ihres Oberflächen Bgiffs, Ges. Abhandl., Leipzig-Berlin, Vol. 2 (1911), pp. 131-229.

[23] J. C. C. NitsCHE, The smallest sphere containg a rectifiable curve, Amer. Math. Monthly, 78 (1971), pp. 881-888.

[24] C. M. Petty, On the geometry of the Minkowski plane, Riv. Mat. Univ. Parma, Vol. 6 (1955), pp. 269-292.

[25] L. S. Pontryagin, V. G. Boltyanskit, R. V. Gamkerlidze, and E. F. Mishchenko, The Mathematical Theory of Optimal Processes, translated from the Russian by K. N. Trirogoff, edited by L. W. Neustadt, Interscience Publishers, New York, 1962.

[26] H. Rutishauser, AND H. SAmelson, Sur le rayon d'une sphere dont la surface contient une courbe fermée, C. R. Acad. Sci. Paris, 227 (1948), pp. 755-757.

[27] S. L. A. SanTALó, Introduction to Integral Geometry, Paris, Hermann, 1953.

[28] B. SEgRE, Sui circoli heodetici di una superfilcie a curvature, che contengono nell'interno una linea assegnata, Boll. Un. Mat. Ital., 13 (1934), pp. 279-283.

[29] J. SCHAER, An "obvious" but useful theorem about closed curves, Math. Mag., (1972), pp. 154-155.

[30] F. A. Valentine, Convex Sets, Krieger, 1976. 